\title{
BUILDING SUSTAINABILITY THROUGH COLLABORATIVE PLANNING
}

\author{
V. GHOMASHCHI \\ University of Prince Edward Island, Canada. \\ Town of Stratford, PEI, Canada.
}

\begin{abstract}
Collaborative planning can influence efforts to build social capital and make consensus towards sustainability and sustainable development. The present study attempts to demonstrate the crucial role of social capital and capacity building as 'tools' and 'targets' of the sustainability journey. This paper briefly reviews the sustainability literature related to planning. Considering the collaborative approach to planning and the associated concepts, the present study aims to make a link between collaborative planning and sustainability. Finally, this paper suggests two conceptual models to explore and explain the interaction and implications of social capital and sustainability. The first model considers sustainability through an integrated dynamic system and explores how collaborative planning can generate sustainability through capacity building. The second model will present a framework of thinking and acting for collaborative sustainability.
\end{abstract}

Keywords: capacity building, collaborative planning, social capital, sustainability, sustainable development.

\section{INTRODUCTION}

Through remarkable environmental debates of the 1970s and the early 1980s, in different contexts and scales, the concept of 'Sustainability and Sustainable Development' was initiated and developed as the driving force for bringing fundamental change and creating a harmony between the environmental protection, social well-being, and economic growth [1].

Over the last decade, throughout the developed and developing nations, scientists, politicians, decision makers, and world organisations have acknowledged the environmental problems such as pollution, deforestation, global warming, and climate change. Such issues are complex problems, requiring solutions which are not only scientific and technical but also social and economic [2-10].

As part of these attempts, two streams of thought have been developed broadly in the area of planning and development.

The first is 'Sustainability' and/or 'Sustainable Development' as described and developed by many scientists, politicians, and organisations around the world from various perspectives [3, 4, 9, 11, 12].

The second is 'Collaborative Planning' as developed in the work of several planning scholars [2, $13,14]$. Both concepts focus on interactive relationships with key stakeholders of planning and development. The two mainstreams of thought stress the complexity of the interactions that take place at different levels and in various types of human habitats. Also, both emphasise citizen participation and empowerment as key elements of planning and development processes and outcomes. The 'Collaborative Sustainability' concept presented here is an attempt to make a realistic linkage between these two streams of thought.

While some economists, politicians, and sociologists believe unsustainability is the ultimate outcome of human intervention in the world, many consider human capital as a driving force for social mobilisation towards sustainability. Nowadays, we require a shared recognition of the need to acknowledge the central role of people as a prerequisite for success of sustainability policies and programmes. Such an approach might be considered as a new episode of similar traditional concepts that have been raised since the 1960s by several urban scholars and sociologist, such as Jane Jacobs [15]. A shared understanding of sustainability may lead to an increasing awareness that various paths can 
be taken to achieve sustainability. However, there exists a general agreement that no sustainable plan can be achieved unless it is well anchored in the public consultation, consensus, and collaboration with the society in question [16].

More recently, many community planning scholars and practitioners have become increasingly sensitive to the relationship between sustainability and collaborative planning. Subsequently, community capacity building and citizen empowerment in decision making and planning processes have been widely considered in theory and practice $[3,4,6,9,11-13,16]$.

What does sustainability mean? How can sustainability goals be achieved? How can we build social capital towards sustainability? How does collaborative planning fit within this discourse? Answering such questions requires a precise definition of sustainability and an explorative study of the role of people in the sustainability journey. A vital task ahead is to elaborate, more systematically, as to how collaborative planning can influence efforts to build social capacity and support people in moving out of deficiency in its multiple forms, towards consensus for sustainability. The present study attempts to demonstrate the crucial role of social capital and capacity building as 'tools' and 'targets' of the sustainability journey.

The remainder of the article consists of seven sections. Section 2 briefly reviews the sustainability and sustainable development literature. The significant role of sustainability in community planning is studied in Section 3. The fourth section examines the key issues that bring both collaborative planning and sustainability together. The concepts of social capital, consensus building, and sustainability are presented in the fifth section. The relationship between sustainability culture and shared values is explored in Section 6. Section 7 suggests a conceptual model which describes how collaborative planning can generate sustainability through social capital and capacity building. Section 8 concludes the article.

\section{SUSTAINABILITY AND SUSTAINABLE DEVELOPMENT}

The word 'Sustainable Development' entered the literature of international relations in the late 1980s [1]. Since then, both sustainable development and sustainability have been used together and become increasingly important strategic issues for all the key stakeholders of the world society. In fact, sustainability and sustainable development have been rapidly moving from the margin to the mainstream of politics, business, science, and planning.

Sustainable development (and sustainability) literature has strongly focused on the following four areas: 1) the definition of sustainable development, its scope, principles, and vision; 2) the process of sustainable development; 3 ) the role of governments and communities in achieving sustainable development goals; and 4) the impact of intervention of organisations and institutions involved in sustainability $[2-7,9,12]$.

Over the past few decades, considerable attention has been paid to sustainability presenting several different definitions and interpretations of sustainable development. However, both 'Sustainability' and 'Sustainable Development' have remained complex ideas that have been neither precisely described nor simply applied. The two concepts are normative, subjective, and ambiguous.

As a general definition 'Sustainable Development' is simply to provide for the fundamental human needs without exploiting nature. Having had such a general definition, I shall restrict myself to the most famous quote of the Brundtland Commission [1].

'Development that meets the needs of the present without compromising the ability of future generations to meet their own needs'.

The present study considers sustainability as a conceptual approach to the development seeking a balance between the Earth, natural ecosystem, and human needs. In other words, sustainability can be defined as a pathway to sustainable development. 
Since, the present study aims to explain the role of 'Collaborative Planning' in achieving sustainability and/or sustainable development. I, therefore, employed terms sustainability and sustainable development in the same way. The term sustainability refers, here, to both sustainability and sustainable development.

As noted, since the definitions of sustainability have been subjective, normative, and ambiguous, considerable efforts have been made to explain the nature, aspects, and scope of sustainability which is the main focus of this study.

For instance, Grosskurth and Rotmans [8] indicated four main characteristics of sustainability:

1. Sustainability is an intergenerational phenomenon;

2. Sustainability is a multi-level scale approach ranging from local to global;

3. Sustainability consists of three main domains: economic, ecological, and socio-cultural;

4. Sustainability is defined and explained through different perspectives and interpretations.

Considering the above characteristics, three main pillars of sustainability have been recognised. Economic sustainability focuses on efficient use of resources and infrastructures as an essential part of development; social sustainability is looking for justice, equal opportunity, and fair distribution of resources, health, and quality of life for people. The main focus of ecological/environmental sustainability is the protection and preservation of the natural environment and the ecosystem [5].

How can we make a reasonable and achievable balance among these three inter-related dimensions of sustainability in practice?

Since the early $1980(\mathrm{~s})$, the international research community has made numerous attempts to address this concern. Remarkable progress has been achieved, and as a result, two new pillars, $\mathrm{Cul}$ tural and Governance, have been added to sustainability. However, there has been far less progress in elaborating and operationalising the role of people and social capital in the sustainability process.

From a social perspective and considering the role of citizens in sustainability, Giampietro [17] defined sustainable development as the capacity of citizens to move from satisfactory to adaptable and viable conditions, in a certain time period [17].

This means that the extent to which people would be prepared to make decisions in favour of sustainability depends on the awareness, knowledge, expertise, and values they have acquired on sustainability during their participation in policy-making process. In other words, the development of a just, healthy, and sustainable society depends on people's values and their way of thinking and acting towards sustainability. For this reason, the concept and approach of sustainability and sustainable development should be integrated into all levels of communication, collaboration, planning, and decision-making process.

\section{SUSTAINABILITY AND COMMUNITY PLANNING}

Since the beginning of the new millennium, the concept of sustainability has become a dominant framework of many economic and social development plans for local communities. As a result, sustainability has emerged as a key issue in community planning literature.

In the context of planning, many scholars and professional planners suggest a holistic view as an essential approach to long-term sustainability planning. Some argue that adopting a systems approach requires seeing the interaction between sustainability dimensions, people, and government [11]. In an urban context, considering the city as a complex system it has been recognised that all parts of the urban system are interrelated and interact with each other. Accordingly, the four dimensions of sustainability, that is economic, social, cultural, and environmental are interrelated and interdependent. These dimensions should, therefore, be considered equally in sustainability planning and in the decision-making process. 
In order to achieve this objective, some planning institutions (e.g. the International Centre for Sustainable Cities) stress on participatory engagement and emphasise that integrated long-term sustainability is an ongoing dynamic process and is best achieved through participatory planning. They refer to multi-sector and multi-stakeholder groups as leaders whereby multi-disciplinary teams serve as the staff to the process $[11,18]$.

As a parallel approach, the present study argues that sustainability is a process rather than a specific pattern, set of principles, criterion, or rules. I stress here that sustainability should not be considered as a development programme and/or a project using certain resources and seeking completion in a definite period of time. Rather, as the key point the present study emphasises that sustainability is a global journey towards sustainable quality of life and well-being for present and future generations. Thus, this paper attempts to demonstrate that sustainability should be considered as a part of a community's values. This means that sustainability should be the mainstream of people's way of life. Having such a definition and scope of sustainability, the paper examines the line of reasoning that deduces collaborative planning as the most important conceptual approach in exploring the role of community capacity building and social capital in such a sustainability journey.

Community planning studies reveal diverse obstacles to broad involvement and the high level of activeness envisioned by proponents of sustainable community development. In searching for ways to overcome these barriers, planning scholars and policymakers have suggested the idea that we can create more sustainable communities through enhancing the local capacity of social capital. With this regard, most models of sustainable community planning stress the importance of widespread participation in the decision-making process $[10,11]$.

Considering community capacity, Roseland [12] identified six forms of community capital as the foundation for sustainable community development. These are: natural, physical, economic, human, cultural, and social capital. He emphasises that for sustainable community planning we should minimise the consumption of natural capital; increase human, social, and cultural capital and improve the physical and economic capital [12]. He also stresses that increasing social capital requires attention to effective governance; strong organisations; capacity building and participatory planning; access to information; and collaboration and partnership [12].

Bridger and Luloff [10] stressed that before social capital is considered as a central element of a public policy, much work should be done in terms of developing a more precise definition of the concept, situating it within extant theories of community, constructing better measures of social capital, documenting the activities and networks most important in building social capital, and gaining a better understanding of the forms of social capital that are most important in developing sustainable communities [10].

Thus, considering two key issues of sustainability as the 'process' of development and sustainability as the 'outcome' of community planning, it would be evident that people's effective participation in the sustainability process is essential and fundamental. How can such a widespread effective participation be achieved?

In the following parts of this essay, through developing two conceptual models, I attempt to explain how sustainability can be achieved through collaborative planning focusing on capacity building and social capital.

\section{COLLABORATIVE PLANNING, SOCIAL CAPITAL, AND SUSTAINABILITY}

In order to explore and to explain the role of people in planning process, there has been remarkable focus on communication, participation, and interactive planning in theory and practice, over the past decades $[2,14,15,19-24]$. Through such valuable efforts, the collaborative approach to planning has been progressively defined and developed. The collaborative planning approach is principally 
based on the two-way interactive communication between people and planning authorities in the planning process. Collaborative planning is an interactive process of consensus building and implementation with higher involvement of stakeholder and public participation [20, 21]. Collaborative efforts have also been referred to as partnerships, consensus building, community-based collaboration, and alternative problem-solving efforts [19].

As a new way of governing environmental sustainability issues, some approaches identify an alternative to the government-centred process while focusing on empowering stakeholders and citizens to play an effective role in planning and decision-making processes [19].

Most of these approaches emphasise that collaborative planning facilitates the interaction between government, residents, and all other stakeholders in the form of a partnership through consensus building, planning, and implementation. In her valuable book 'Collaborative Planning', Patsy Healey developed an institutional approach to social, economic, and environmental dynamics, to elaborate this process. She emphasised the importance of understanding concerns and addressing the collective concerns through a collaborative planning process [13].

In a similar way, the key issue which is considered here is that the collaborative planning in the decision-making process depends on the stock of 'Social Capital' of a community. However, social capital itself builds upon shared systems of meaning and the extent of consensus within the community.

As noted, this study attempts to explore the role of social capital and its component in the process of collaborative planning towards sustainability. In other words, I will explain how collaborative planning approach can increase social capital of a community as one of the main driving forces of sustainability. Exploring the relationship between sustainability and people in a sustainable development process requires definitions and explanations of social capital and shared values of a society.

\section{SOCIAL CAPITAL, CONSENSUS, AND CAPACITY BUILDING}

The term social capital refers to the relationship, networks, and norms that facilitate collective action [12]. For some, social capital is the shared knowledge, understanding, and patterns of interactions that a group of people bring to any productive activity [25, 26]. Putnam [26] argued that social capital can enhance physical and human capital of a community. Through a parallel approach, Roseland claimed that social capital is created when members of a society learn to trust each other so that they are able to make credible commitments and rely on global forms of mutuality rather than on narrow sequence of specific interest relationship [12].

The association and interaction between social capital and capacity building has been discussed by several scholars through various approaches to social policy and development planning [13, 14, 27]. To gain a clearer understanding of how social capital can build consensus and mobilise social action, it is crucial to consider its individual components in more detail.

Innes et al., in their Consensus-Building concept, identified three types of human capital which are important in sustainability discourse. They are: social, intellectual, and political capital. For them, social capital can be defined as trust, norms of behaviour, and networks of communication; intellectual capital as a shared understanding of the facts leading to common meanings for discussion and a move towards agreement on policy issues. They consider political capital as agreement on proposals to create a better mutual view of the outside world and a better political position. They emphasise that all these three types of capital are interconnected, and the absence of any one will affect the effectiveness of the others [14].

With a slight modification, instead of political capital, I refer 'Consensus' as the third component of human capital. Accordingly, it might be said that social capital includes social relations, shared knowledge and values, and trust in a society. I also argue that increasing social capital of community can enhance and protect natural, physical, and human capital of the community. 
In the process of consensus building social relations together with shared knowledge and trust would play crucial roles. Furthermore, it is argued that trust is the main source of social consensus within a community. Trust, itself, is generated and enhanced through social relations, sincere and effective communication, and shared knowledge. The key questions raised are: How do these components interact in the process of collaborative planning? What are the roles and functions of consensus and trust in building social capital? And, how can we achieve sustainability through capacity building?

Developing the Collaborative Sustainability approach, two conceptual models presented here attempt to simplify the argument and answer the questions. The first model presents the sustainability framework, the elements, and their interrelationship during the process of sustainability (Fig. 1).

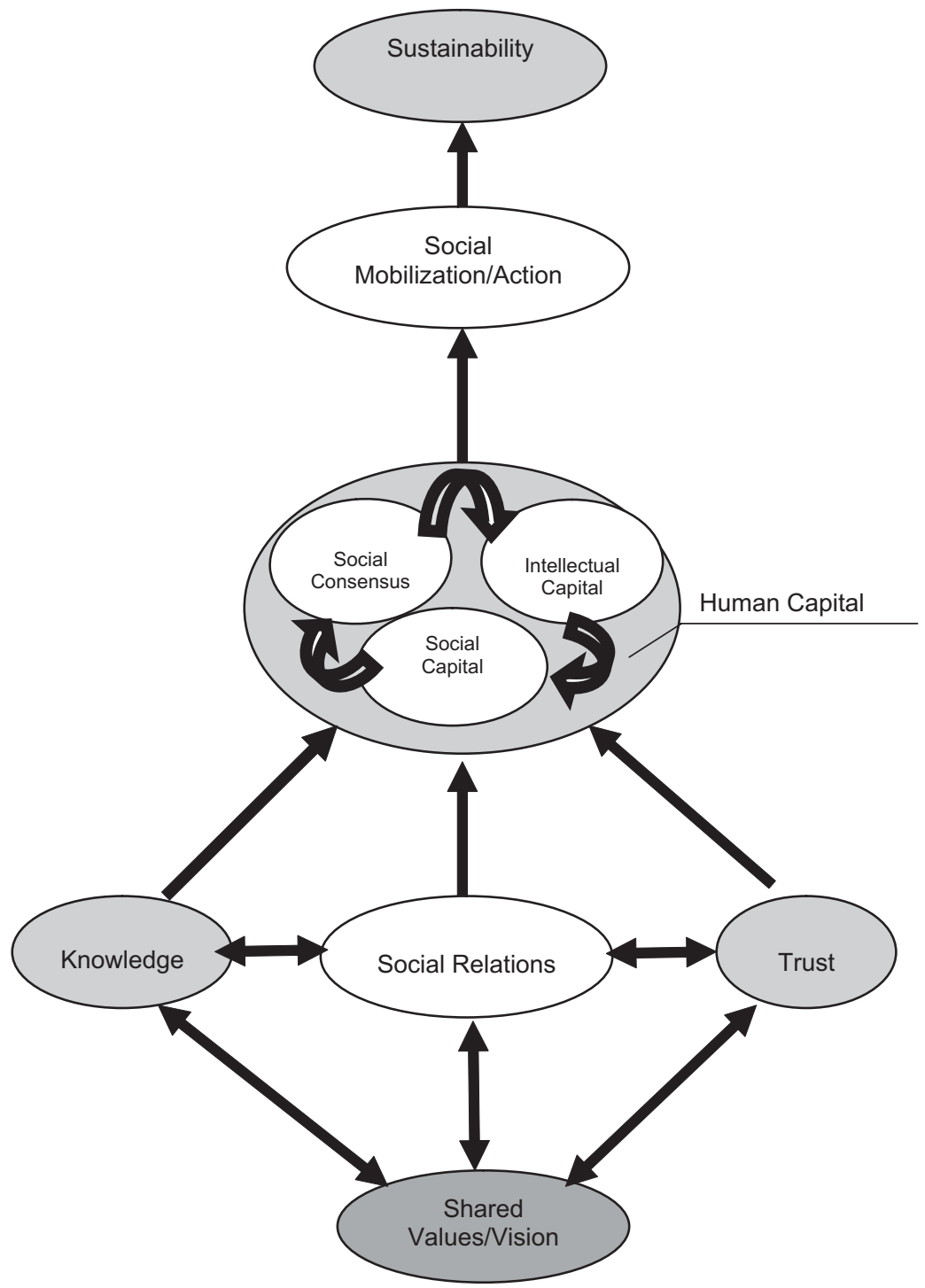

Figure 1: A conceptual framework of collaborative sustainability. 
Human capital of a society itself consists of three main elements: social capital, political capital, and intellectual capital. It should be noted that, in the current study 'capital' refers to the stock of wealth, resources, and assets (such as the natural and built environment), as well as political power, knowledge, and skills that exist in a community. And, 'capacity' refers to a potential capital, the capability of becoming future capital.

Considering the proposed definitions, social capacity, together with intellectual capacity (knowledge), creates a great potential and capability in both society and individuals for causing changes towards sustainability.

However, the extent of social relations depends on the degrees of both Trust and Consensus that exist among the community members and between the community and the government. Similarly, the range of people's knowledge will be increased when consensus building improves within the community (Fig. 1).

As the model in Fig. 1 shows, the source of human capital of a community is shared values/vision. Shared values/vision can generate trust and consensus between individuals. Trust is the most important feature of social capital because it increases the likelihood of co-operation, which in turn strengthens trust. Trust is based on sincere social relations and familiarity with other members of the community [10].

In other words, trust is the vehicle of social relations. This means that trust leads to an improvement in social relations. This, in turn, improves social capital and consequently, increases social mobilisation in society towards shared goals.

Moreover, consensus helps to share understanding of the facts. This, in turn, increases people's knowledge as another source of human capital. This again increases capability for social mobilisation of the society [28].

Accordingly, I argue here that the improvement of social capital leads to the strengthening of collective intellectual capacity, and this capacity leads to the enhancement of the capability of society. All politicians, planners, and decision makers need, therefore, to consider all these aspects of community capital during the sustainability journey. That means that in our collaborative approach to sustainability, we should focus on generating people's shared values towards sustainability and building community capacity rather than setting tangible objectives, technical tools, and regulations. Having had this conceptual model, the study aims to elaborate the role of collaborative planning in the capacity building process.

\section{SUSTAINABILITY CULTURE AND SHARED VALUES}

As a general concept, 'culture' refers to people's way of thinking and acting. It has been clarified that culture is based on some shared system of meanings and beliefs in the society which were termed values. Also, culture has been defined as the 'glue' of the society; i.e. in the absence of culture, the society will be without shared system of meanings.

As a specific concept in the context of this study, culture (or the culture of sustainability) has been defined as a set of values, attitudes, and system of meanings towards sustainability generating the way of thinking and acting in the society.

The research suggested that sustainability is shaped by people, and sustainable development cannot be achieved unless people hold shared values and systems of meaning towards sustainability. Thus, the sustainability culture as the glue of the society is an essential part of sustainability. Sustainability culture must be considered in all aspects of urban life. Also, this research emphasises that sustainability values play a significant role in the inter-relationship between social, economic, and environmental dimensions of development.

This study has emphasised the role of sustainability values as the driving force of sustainable development by revealing the central importance of such shared values in consensus and social 
mobilisation. The research has pointed out that the growth of morality and shared sustainability values can improve shared understanding and create consensus in the society, which in turn can rectify social relations as well as the local knowledge of the society leading to a more efficient use of the material resources and changing environment. Such cultural/sustainability values have the capacity to generate co-operative energies in development projects.

Accordingly, people in both developed and developing nations, can create a sustainable and strong social system based on shared values and system of meanings among individuals as members who feel commitment and obligation to such meanings and follow the rules and principles of sustainability. The more people hold shared sustainability values, the more sustainability in the society.

\section{SUSTAINABILITY THROUGH COLLABORATIVE PLANNING AND CAPACITY BUILDING}

In her collaborative approach to development planning, Patsy Healey [13] suggested five significant concepts which concern building collaborative relationships with development 'stakeholders'. They are identified as integrative place-making, collaboration in policy-making, broad stakeholder involvement, using 'local' knowledge, and building 'relational' resources. She emphasises the last two, local knowledge and relational resources as the bases of social capital [13]. Healey stressed that the institutional capacity of society will be created through increasing both the 'knowledge-ability' and 'relational capacity' of society. Social capital as the capacity to organise for social action itself depends on the extent of local knowledge and on the relational capacity of society [13].

Chaskin [29] defined societal or institutional capacity as the interaction of human capital, organisational resources, and social capital within the community. He believed that such a capacity can analyse, understand, and solve the collective problems [29].

Through a similar approach, Foster-Fishman et al. [30] identified the four essential levels for community collaborative capacity building as: within members, within their relationships, within their organisational structure, and within the programmes they sponsor [30].

Similarly, Innes and Booher [20] identified four categories of capacity building: individual, organisational, relational, and governance capacity.

Innes and Booher defined individual capacity building as the development of personal skills and knowledge in order to enhance communication, increase co-operation, resolve conflicts, and respect others as well as to empower individuals in planning policies, making decisions, implementing and evaluating programmes and projects. An individual with more capacity understands his/her position as an important part of a larger system and has more creative ideas and initiatives [20].

Organisational capacity building seeks improvement in both internal and external well-networked communication. Organisational capacity building refers to enhancement of shared skills and information as well as mutual trust and shared understandings of the problems and the alternative responses. A well-built organisational capacity would have the potential to respond quickly to the unexpected situations. Relational capacity focuses on collaboration, coalitions, partnerships, as well as interagency and inter-jurisdictional relationships. Information and knowledge will be shared through a collaborative learning process for building relational capacity. Thus, constructive communication would diminish conflicts and engage diverse interests and attitudes in developing and implementing new plans [20].

Also, collaborative planning improves the governance capacity through encouraging diverse voices and interests. It facilitates the flow of information to all stakeholders and empowers them to play an effective role in governance. A well-developed governance system provides a collaborative community whereby members have strong communication skills and facilities to share their information, knowledge, and experiences. Thus, community members have real participation 
in the governance of their future. From a collaborative planning perspective, such a governance system would have a developed network of working relationships among different sectors: business, social, and cultural groups. These sectors will collaborate to work towards understanding and analysing sustainability and the challenges in their community and exploring the ways to respond.

Through a related approach, many development professionals and world organisations emphasise that while sustainable development is usually linked to environmental, social, and economic issues, the important role of education and capacity building in sustainability process is undeniable $[1,31-33]$.

All these concepts stress that capacity building is a process of improvement in learning, information flowing, communication, social relations, and collaboration in decision making and action. In other words, collaborative planning is the approach that would conceptualise, formulate, and facilitate capacity building. That means that collaborative planning can be a process of capacity building towards sustainability achievements.

Accordingly, it is argued that social action towards sustainability will emerge when members of a society rely on their shared knowledge and common interpretive frameworks. In other words, members of a society understand their shared visions and goals by a distinct rationale, through the application of their own values. In a similar way, it is emphasised that socially shared meaning is derived from the application of people's shared values and these foster and promote social mobilisation.

Considering the concepts mentioned above, the dynamic conceptual model presented here explains the process of capacity building through collaborative planning towards sustainability. The model emphasises on Trust, Knowledge, and Social Relations as the three most significant factors in building human capacity in a society. According to this model, building the human capacity of a society based on people's shared values will increase the extent of consensus among the society. This, in turn, will foster social action towards the society's sustainability goals and objectives (Fig. 2).

As the model shows, shared values and vision would perform as a foundation and a driving force of sustainability. The relationship between social capital, shared values, and sustainability is also simplified in the proposed conceptual model (Fig. 2). This model illustrates how social capital and shared values will act as the driving force of sustainability.

According to the present study, people participation in the policy and decision-making process should be considered as a key component of sustainability and sustainable development. Building and expanding effective people participation in the sustainability journey should be the central theme of every sustainability plan and initiative. An integrated sustainable development plan should focus on community capacity building, increasing social capital and citizen empowerment in the decision making through a collaborative planning process.

As a multi-dimensional activity, collaborative planning for sustainability would concentrate on building social capital while considering all other forms of sustainability. Furthermore, sustainable planning and development would build the community capacity through improving trust, increasing knowledge, and developing social relations among members. This leads to emerging shared vision and goals and thereby builds common grounds for initiating policies and strategies towards sustainability. Building human capacity (individually and collectively) in a society forms the basis from which social, economic, and environmental sustainability can be achieved.

The question may rise: could education and capacity building be misused by planners and decision makers during the development process? 


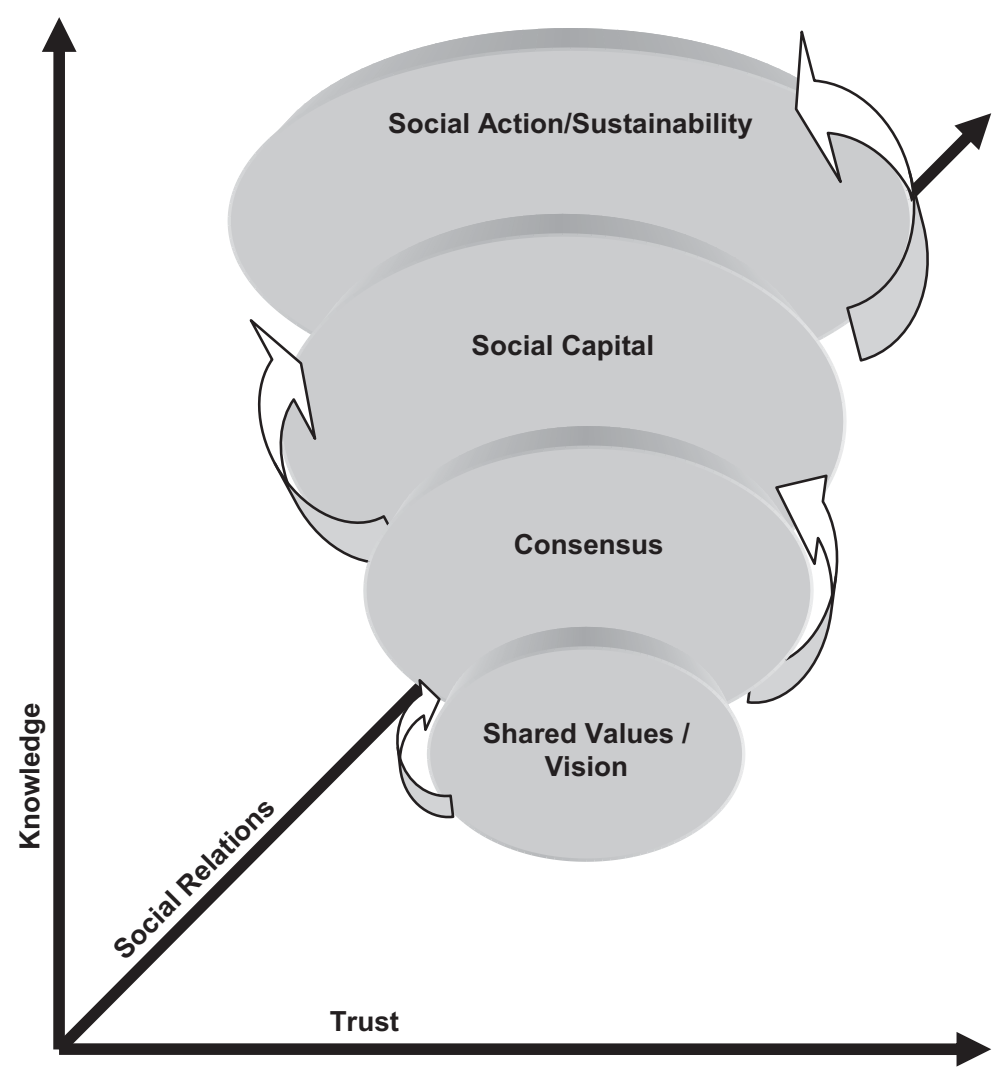

Figure 2: Dynamic model of sustainability through social capital and capacity building.

In his 'Communicative Action Theory', Jürgen Habermas, the well-known German philosopher, has addressed this issue wisely [34]. Borrowing Habermas' [34] communicative action theory we should consider the following points in the collaborative planning process:

First, planning authorities would only facilitate the collaboration process. They are not supposed to impose any ideas or interests on the community.

Second, the collaboration process is an interactive two-way communication avenue. Planners and decision makers would learn while educating others.

Third, there are five key principles to legitimise such a two-way communication avenue including: i) providing equal opportunity for everyone to access to information; ii) using a common and understandable language; iii) the communication and collaboration process is full of sincere and respect to everyone; iv) there is no pre-judgement or pre-planned decision, i.e. every single alternative should be presented and discussed equally; and v) everyone should be committed to the final decision agreed by stakeholders. Having had these prerequisites, there would be very little chance for planning authorities and/or decision makers to misuse the collaboration process and impose their own plans and projects.

\section{CONCLUSION}

Considering the present unsustainable situation of the world there is an urgent need to address sustainability and sustainable development in new and innovative ways. 
The main objective of this paper was to build a conceptual framework for elaborating the interaction between capacity building and collaborative planning while exploring associated implications for achieving sustainability. The paper aimed to explore the vital necessity of collaborative planning and capacity building in achieving sustainability.

The study claims that sustainability requires collective social action. Such social action itself is rooted in people's shared values. This study has also emphasised the role of sustainability values as the driving force of sustainable development by revealing the central importance of such shared values in social solidarity and social mobilisation. Hence, in a discourse on sustainability, understanding and building people's shared values is a vital task. This means that people including development planners, scholars, and decision makers need collective central rules and values. These shared systems of meanings are fundamental to communication, understanding, and collaboration.

As a multi-dimensional activity, collaborative planning for sustainability should concentrate on building social capital while considering all other aspects of sustainability. In addition, according to the present approach, social capacity building based on improving trust, increasing knowledge, and developing social relations among the society should be considered as both tools and targets of sustainability.

This essay emphasised that social, environmental, and economic sustainability is the result of community development and changes in people's system of reasoning. According to the collaborative sustainability approach, sustainability achievement requires inclusive participation from all stakeholders: agents, agencies and, in particular, common people. Collaborative sustainability would attempt to create extended social relations between all parts of a society at different levels in order to generate and enhance trust and consensus among them. This leads to building shared vision and goals of sustainability as well as identifying common ground for initiating sustainable policies and strategies. Integrated sustainable social, economic, and environmental initiatives will flow through such policies and strategies.

\section{REFERENCES}

[1] WCED The World Commission on Environment and Development (The Brundtland report), 1987.

[2] Goldstein, B. \& Butler, W., Expanding the scope and impact of collaborative planning. Journal of the American Planning Association, 76(2), pp. 238-249, 2010. doi:http://dx.doi. org/10.1080/01944361003646463

[3] Dwivedi, O, Kyba, P., Stoett, P. \& Tiessen, R., Sustainable Development and Canada: national and international Perspectives, Broad View Press: Peterborough, Ontario, Canada, 2010.

[4] Sumner, J., Sustainability and the Civil Commons, Rural Communities in the Age of Globalization, University of Toronto Press: Toronto, 2007.

[5] Martens, P., Sustainability: Science or Fiction? Sustainability: Science, Practice \& Policy, 2(1), pp. 36-41, 2006.

[6] Edwards, A., The Sustainability Revolution: Portrait of a Paradigm Shift, New Society Publishers, Gabriola Island, Canada, 2005.

[7] Ehrenfeld, J., The Roots of Sustainability. MIT Sloan Management Review, 46(2), pp. 23-25, 2005.

[8] Grosskurth, J. \& Rotmans, J., The scene model: getting grip on sustainable development in policy making. Environment, Development and Sustainability, 7(1), pp. 135-151, 2005. doi:http://dx.doi.org/10.1007/s10668-003-4810-0

[9] Reez, W., Globalization and Sustainability: Conflicts or Governance? Bulletin of Science, Technology and Society, 22(4) pp. 249-68, 2002.

[10] Bridger, J.C. \& Luloff, A., building the sustainable community: is social capital the answer? Sociological Inquiry, 71(4), pp. 458-472, 2001.

[11] Seymoar, N., The Sustainable Cities, PLUS Planning Cycle, 2008. 
[12] Roseland, M., Towards Sustainable Communities, New Society Publisher: Gabriola Island, BC, 2005.

[13] Healey, P., Collaborative Planning, Macmillan: London, 1997.

[14] Innes, J., et al. Planning Through Consensus-Building; A New View of the Comprehensive Planning Ideal, University of California IURD: Berkeley, 1995.

[15] Jacobs, J., The Death and Life of Great American Cities, Random House: New York, 1961.

[16] Thierry, V. \& Tyndale, W., Culture, spirituality, and development, in Development and Culture, Edited by D. Eade, Kumarian Press, Sterling USA, pp. 1-24, 2002.

[17] Giampietro, M., Complexity and scales: the challenge for integrated assessment. Scaling in Integrated Assessment, eds J. Rotmans \& D. Rotmans, pp. 293-327, 2003.

[18] Innes, J.E. \& Booher, D.E., Consensus building and complex adaptive systems - a framework for evaluating collaborative planning. Journal of the American Planning Association, 65(4), pp. 412-423, 1999. doi:http://dx.doi.org/10.1080/01944369908976071

[19] Koontz, T., Collaboration for sustainability? A framework for analysing government impacts in collaborative-environmental management. Sustainability: Science, Practice, \& Policy, 2(1), pp. 15-24, 2006.

[20] Innes, J.E. \& Booher, D.E., Collaborative policymaking: governance through dialogue, Chapter 1 in Deliberative Policy Analysis: Understanding Governance in the Network Society, edited by Hajer, Maarten and Hendrik Wagenaar., Cambridge University Press, Cambridge, UK, pp. 33-59, 2003. doi:http://dx.doi.org/10.1017/CBO9780511490934.003

[21] Margerum, R., Collaborative planning: Building consensus and building a distinct model for practice. Journal of Planning Education and Research, 21(3), pp. 237-253, 2002. doi:http:// dx.doi.org/10.1177/0739456X0202100302

[22] Forester, J., Planning in the Face of Future, University of California Press: Berkeley, 1989.

[23] Healey, P., Building Institutional capacity through collaborative approaches to urban planning. Environment and Planning A, 30, pp. 1531-1556, 1998. doi:http://dx.doi.org/10.1068/a301531

[24] Friedman, J., Retracking America: A theory of transactive planning, Anchor Press: New York, 1973.

[25] Coleman, J.S., Social capital in the creation of human capital. American Journal of Sociology, 94, pp. 95-120, 1988. doi:http://dx.doi.org/10.1086/228943

[26] Putnam, R.D., Bowling alone: America's declining social capital. Journal of Democracy, 6(1), pp. 65-78, 1995. doi:http://dx.doi.org/10.1353/jod.1995.0002

[27] Smith, C., Moral, Believing Animals: Human Personhood and Culture, Oxford University Press: New York: NY, 2003.

[28] Coplin, J., Text and Context in the Communication of a Social Movement's Charisma, Ideology, and Consciousness: TM for India and the West, Unpublished PhD dissertation, University of California: San Diego, 1990.

[29] Chaskin, R., Defining Community Capacity: A Definitional Framework and Case Studies from a Comprehensive Community Initiative Urban Affairs Review, 36(3), pp. 291-323, 2001.

[30] Foster-Fishman, et al., Building collaborative capacity in community coalitions: a review and integrative framework. Journal of Community Psychology, 29(2), pp. 241-261, 2001. doi:http://dx.doi.org/10.1023/A:1010378613583

[31] Breidlid, A., Culture, indigenous knowledge systems and sustainable development: A critical view of education in an African context. International Journal of educational development 29, pp. 140-148, 2009. doi:http://dx.doi.org/10.1016/j.ijedudev.2008.09.009

[32] WSSD World Summit on Sustainable Development Plan of Implementation, 2002.

[33] UNESCO Education for Sustainable Development, 2008.

[34] Habermas, J., The Theory of Communicative Action: Vol. 1: Reason and the Rationalisation of Society, Polity Press: London, 1984. 